\title{
Impact of glycation on duodenal digestibility of Bowman-Birk inhibitors
}

\author{
J. M. Silván and M. D. del Castillo \\ Instituto de Fermentaciones Industriales (CSIC), C/ Juan de la Cierva 3, 28006 Madrid, Spain
}

\begin{abstract}
Adverse effects of soyabean-containing diets include poor digestibility and allergy to soyabean proteins. To improve the nutritional quality of soya foods inhibitors are generally inactivated by heating or eliminated by fractionation during food processing ${ }^{(1)}$. These inhibitors could generate an immune response ${ }^{(2)}$. Bowman-Birk (BBI) and Kuntiz (KTI) inhibitors are heat stable and they may be inactivated by glycation ${ }^{(3)}$, which also reduces soyabean-protein allergenicity ${ }^{(4)}$. The aim of the present study was to investigate the impact of the BBI glycation on the activity of duodenal digestive enzymes in order to optimise the beneficial effects of soyabean proteins.

The BBI was glycated with glucose, fructose and fructooligosaccharides (FOS; Raftilose P95; Orafti España SL, Barcelona, Spain) in $\mathrm{KOH}(0.2 \%, \mathrm{w} / \mathrm{v})$ at $60^{\circ} \mathrm{C}$ for $20 \mathrm{~min}$. The protein glycation was confirmed by isoelectric focusing (IEF) and SDS-PAGE gel electrophoresis. In vitro duodenal digestion was performed using the method described by Moreno et al. ${ }^{(5)}$. Samples were incubated with trypsin-chymotrypsin for $120 \mathrm{~min}$.

Fig. 1 shows the IEF gel (pH 3-10) stained with Comassie Blue. Different electrophoretic profiles were obtained for native and heated BBI samples (lanes 1 and 2) compared with BBI glycated with glucose, fructose and FOS (lanes 3-5). A decrease in positive charges was observed as a result of the involvement of basic amino acids (Lys and Arg) in the Maillard reaction (glycation). This analysis also confirmed BBI stability to heat treatment at $60^{\circ} \mathrm{C}$ for $20 \mathrm{~min}$. Heating had no effect on the isoelectric point of BBI. Fig. 2 shows the SDS-PAGE gel $(10 \%, w / v)$ stained with Comassie Blue. The molecular mass $(8 \mathrm{kDa})$ of native BBI (lane 1$)$ was increased as a consequence of glycation with glucose, fructose and FOS (lanes 2-4; Fig. 2(a)). All samples inhibited trypsin and chymotrypsin activities. Samples did not change their electrophoretic profiles after enzymic digestion (Fig. 2(b); lane 1, native BBI; lane 2, heated BBI; lanes 3-5 BBI glycated with glucose, fructose and FOS respectively). Further studies are needed to establish the glycation conditions that cause a reduction in BBI inhibitory activity against digestive enzymes and to identify the glycation product responsible for this change. Both IEF and SDS-PAGE analyses are suitable for following glycation of BBI and other soyabean proteins.
\end{abstract}

Fig. 1

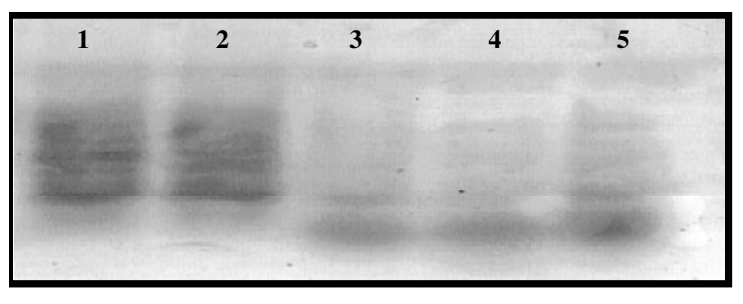

Fig. 2

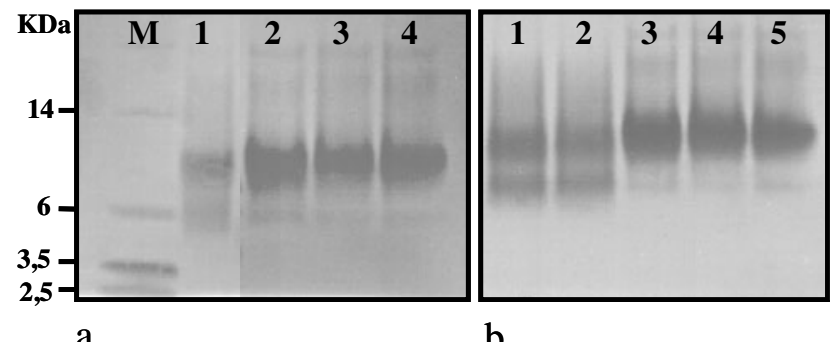

a $\mathrm{b}$

Authors thank ORAFTI for kindly supplying commercial FOS. These studies were funded by projects AGL2004-05031 and ALIBIRD-CM-S0505/ AGR-0153.

1. Friedman M \& Brandon DL (2001) J Agric Food Chem 49, 1069-1086.

2. Kaayla TD (2004) Nexus Magazine 11; available at www.nexusmagazine.com

3. Kato,Y \& Matsuda T (1997) J Agric Food Chem 45, 3826-3831.

4. van de Lagemaat J, Silván JM, Moreno J, Olano A \& Del Castillo MD (2006) Food Res Int 40, $153-160$.

5. Moreno FJ, Mellon FA, Wickham MS. Bottrill AR \& Mills EN (2005) FEBS J 272, 341-352. 